\title{
A Review of Executive Functions in Autism Spectrum Disorder and Attention Deficit Hyperactivity Disorder
}

\author{
Carmen Berenguer ${ }^{1}$, Belen Rosello ${ }^{1} \&$ Geraldine Leader $^{2}$ \\ ${ }^{1}$ University of Valencia, Spain \\ ${ }^{2}$ National University of Ireland, Galway, Ireland \\ Correspondence: Carmen Berenguer, Developmental and Educational Psychology Department, Faculty of \\ Psychology, University of Valencia, Spain. E-mail: carmen.berenguer@uv.es
}

Received: June 29, 2018 Accepted: July 26, 2018 Online Published: August 16, 2018

doi:10.5539/jedp.v8n2p107 URL: http://doi.org/10.5539/jedp.v8n2p107

\begin{abstract}
Autism spectrum disorder (ASD) and attention deficit hyperactivity disorder (ADHD) are two of the most common childhood-onset neurodevelopmental disorders. Literature has shown different patterns of deficits in executive functioning in children with ASD and ADHD. To date few studies have examined executive functions in both ASD and ADHD and with mixed results.

The current study provides the first systematic review to explore distinct executive function components (attention problems, response inhibition, working memory, planning and flexibility) that underlie the specific deficits seen in children and adolescents with both ASD and ADHD disorders. Findings provide evidence for executive dysfunctions across different key components such as attention, response inhibition and verbal working memory in children and adolescents with ASD and comorbid ADHD clinical symptoms. This research explores the neurocognitive profile of the comorbid condition, which is also critical for designing appropriate interventions.
\end{abstract}

Keywords: autism spectrum disorder, attention deficit hyperactivity disorder, comorbidity, executive functions, review

\section{Introduction}

Autism spectrum disorder (ASD) is characterised by deficits in communication, social interaction and restricted and repetitive patterns of behaviours. Prevalence of ASD is considered about $1 \%$ worldwide (Elsabbagh et al., 2012), while attention deficit hyperactivity disorder (ADHD) affects approximately $6 \%$ of children (Polanczyk, de Lima, Horta, Biederman, \& Rohde, 2007) and the main manifestations are inattention, hyperactivity and impulsivity (American Psychiatry Association, 2013). ASD and ADHD are among the most common neurodevelopmental disorders. For the last decades and specially since the Diagnostic and Statistical Manual of Mental Disorders (DSM $5^{\text {th }}$ ed., American Psychiatry Association, 2013) allowed the dual diagnosis, a considerable amount of literature has focused around comorbid condition. Comorbidity between ASD and ADHD has been reported to be within the range of 14-78\% (Gjevik, Eldevik, Fjæran-Granum, \& Sponheim, 2011; Kaat, Gadow, \& Lecavalier, 2013; Mattila et al., 2010). ADHD is one of the most common comorbid disorders in children with ASD (Simonoff et al., 2008), and in a recent review of 35 studies that investigated the co-occurrence between ASD and ADHD found it was of 37 to $85 \%$, in clinic samples (Leitner, 2014; Stevens, Peng, \& Barnard-Brak, 2016). Conversely, 15-25\% of children with ADHD have ASD symptoms (Kotte et al., 2013). Executive functioning $(\mathrm{EF})$ is a term that refers higher-order cognitive processes that guide complex goal-directed behaviors in a dynamic and changing environment. This umbrella term encompasses different metacognitive domains such as response inhibition, working memory, cognitive flexibility planning or fluency (Diamond, 2013). These functions have been linked, in particular to prefrontal cortex suggesting that the brain regions that are important for EF are those affected by ASD (Goldberg et al., 2005; Ozonoff et al., 2004) and ADHD (Goldstein \& Naglieri, 2013; Rubia, Alegria, \& Brinson, 2014). In addition key aspects of EF are compromised in both disorders, and have been identified as potential shared endophenotypes (Rommelse, Geurts, Franke, Buitelaar, \& Hartman, 2011), suggesting the importance of investigating both disorders. Furthermore, the results of genetic, neuropsychological and neuroimaging studies suggest possible pathophysiological links between ASD and ADHD affecting key fronto-striatal and fronto-parietal circuits that are important for performing EF and complex cognitive functions as attentional process (Rommelse et al., 2011). 
The research on the association of symptoms of ASD and ADHD are largely focused on childhood, (Johnson, Gliga, Jones, \& Charman, 2015; Rommelse, Buitelaar, \& Hartman, 2017) despite the impact that changes in EF can have across the lifespan (Hartman, Geurts, Franke, Buitelaar, \& Rommelse, 2016). There are scant studies linking EF deficits to comorbid symptoms of ASD and ADHD in adults (Nydén et al., 2010). Literature has shown different patterns of deficits in executive functioning in children with ASD and ADHD (Rommelse et al., 2011). When comparing both groups in children with ADHD, response inhibition and sustained attention tasks are commonly impaired (Corbett, Constantine, Hendren, Rocke, \& Ozonoff, 2009), but also working memory, vigilance, and planning show strong and consistent deficits (Willcutt, Doyle, Nigg, Faraone, \& Pennington, 2005). On the other hand, EF deficits are also detected in children with ASD who often have difficulties with planning and cognitive flexibility (Happé \& Ronald, 2008; Hill, 2004; Ozonoff et al., 2004). To date many studies have examined EF in ADHD and ASD with mixed findings (Lai et al., 2017; Willcutt et al., 2005). Despite strong evidence on executive functions implication in ASD and ADHD fewer studies have explored EF in comorbid condition. For example, Craig et al. (2016) suggested that there are few and inconsistent findings from EF studies that include individuals with comorbid ASD and ADHD. Therefore this review will update the findings of EF in ASD and ADHD by including studies that explore EF in both conditions. We will also explore the neurocognitive profile of the comorbid condition, which is also critical for designing appropriate interventions.

\section{Method}

\subsection{Search procedure}

The literature was searched using the PubMed, PsycINFO, PsycARTICLES and SCOPUS databases (July, 2017). Additionally we used the combination of the following terms:

Autism, ASD, pervasive development disorder, PDD, and Attention Deficit Hyperactivity Disorder, ADHD, "comorbidity" or "comorbid". We used broad search terms in order not to lose any relevant work.

\subsection{Inclusion and Exclusion Criteria}

To be included in the present systematic review, the articles had to be written in English and published in peer-reviewed journals, between 2000 and July 2017. Titles and abstracts were screened for preliminary inclusion based on a title search and subsequent abstract review. The search was further refined according to the inclusion and exclusion criteria in selected papers that reported on findings relevant in relation to executive functioning skills in ASD and ADHD comorbid group or ADHD and ASD comorbid group: 1) Studies with ASD and ADHD or ADHD and ASD comorbid group; 2) assessed EF domains or skills through standardized test; 3) participants from 3 years to 18 years age; 4) Empirical studies.

A detailed description of the different steps that were taken when searching the literature is provided (Figure 1). 


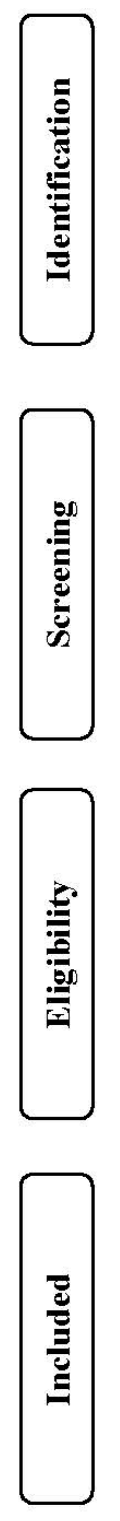

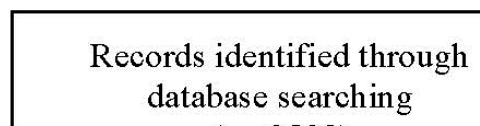

$(\mathrm{n}=2598)$
Additional records identified through other sources

$(\mathrm{n}=53)$

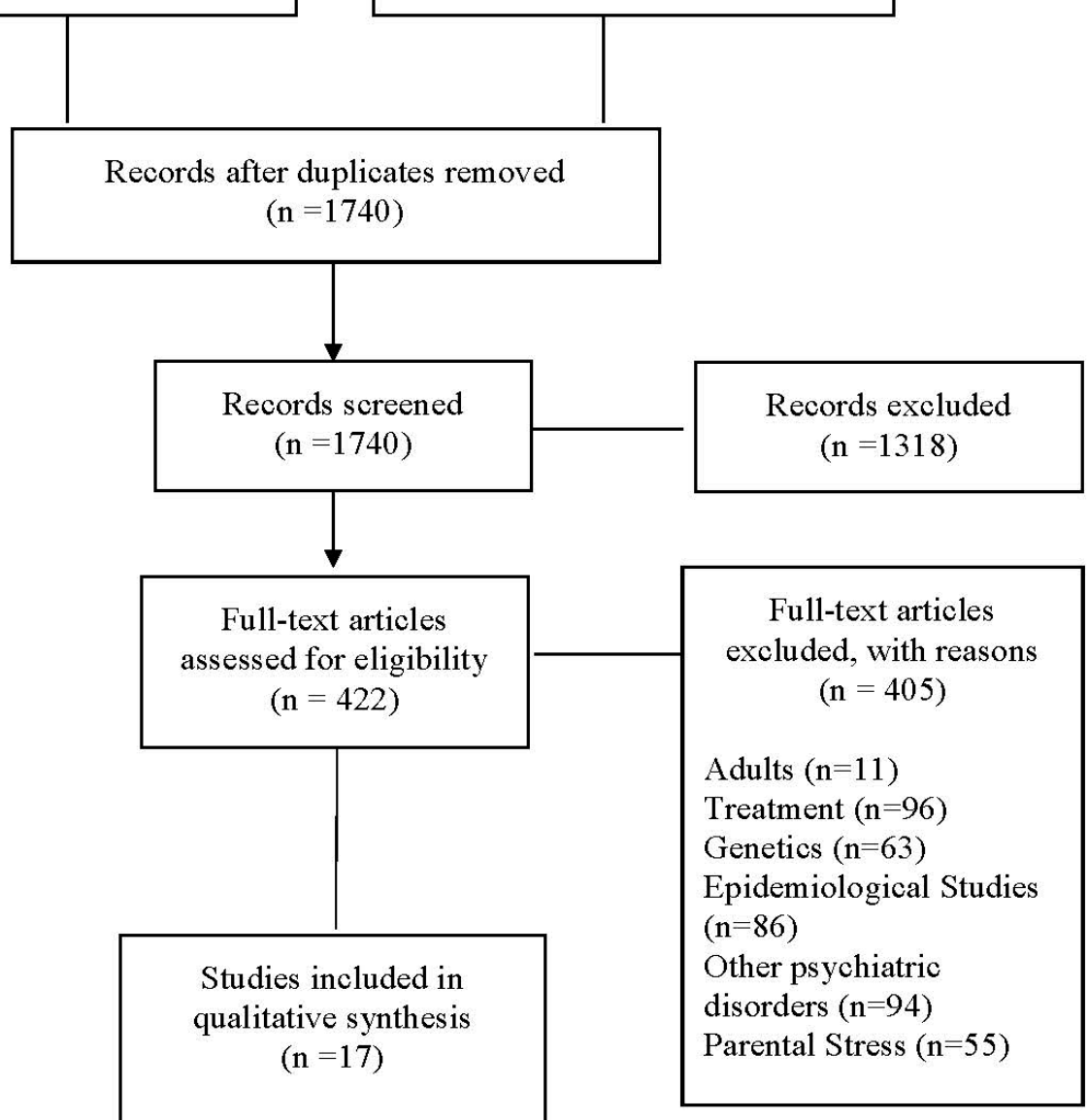

Figure 1. Flow diagram of the systematic review

Source. Adapted from Moher, Liberati, Tetzlaff, Altman, and the PRISMA Group (2009). PloS Med, 6(6). Copyright 2009 by the Public Library Science.

\subsection{Data Extraction}

Studies that met the inclusion criteria were summarized in executive function domains. Each section starts with a brief summary on the executive function domain followed by description of participants, assessment procedure and finally the main findings for comorbid group.

\subsection{Reliability and Inter-Observer Agreement}

The first author and second authors reviewed each study included in the review, independently. Studies meeting criteria for inclusion were scored based on EF in comorbid ASD+ADHD. Disagreements were resolved through discussions among all authors until a consensus was achieved.

\section{Results}

Figure 1 presents a PRISMA flow diagram depicting a summary of our selection procedure. In all, our search yielded 17 papers which were studied carefully for inclusion in this review. Table 1 describes the 17 studies that 
compare executive functions deficits in children and adolescents with comorbid ASD and ADHD or ADHD and ASD. Reference, number of subjects, total IQ, executive functions tasks, executive function domain, key results comorbid group and conclusions are listed.

Table 1. Previous studies that examine executive functions in children and adolescents with ASD + ADHD and $\mathrm{ADHD}+\operatorname{ASD}(\mathrm{N}=17)$

\begin{tabular}{|c|c|c|c|c|c|c|}
\hline Reference & Participant: (N) & $\begin{array}{l}\text { Total } \\
\text { IQ }\end{array}$ & $\begin{array}{l}\text { Executive Functions } \\
\text { Tasks }\end{array}$ & $\begin{array}{l}\text { EF } \\
\text { Domain }\end{array}$ & Results comorbid group & Conclusions \\
\hline $\begin{array}{l}\text { Adamo et al. } \\
(2014)\end{array}$ & $\begin{array}{l}46 \mathrm{ADHD} \mathrm{MA}=10 \\
46 \operatorname{ASD}(\mathbf{1 7} \mathbf{A S D}+) \\
\mathrm{MA}=10 \\
36 \mathrm{TD} \mathrm{MA}=10\end{array}$ & $\begin{array}{l}106 \\
109 \\
112\end{array}$ & $\begin{array}{l}\text { Sustained Attention to } \\
\text { Response Task (SART) }\end{array}$ & Attention & $\begin{array}{l}\text { ASD+ and ADHD shared } \\
\text { elevated amplitudes of } \\
\text { RT-ISV, ASD=TD }\end{array}$ & $\begin{array}{l}\text { ADHD and ASD+ share } \\
\text { common underlying } \\
\text { mechanisms of RT-ISV; }\end{array}$ \\
\hline $\begin{array}{l}\text { Andersen et al. } \\
\text { (2013) }\end{array}$ & $\begin{array}{l}79 \mathrm{ADHD} M A=11.6 \\
\mathbf{1 6} \mathrm{HFA}+\mathrm{MA}=12.2 \\
22 \mathrm{HFA}-\mathrm{MA}=11.9 \\
50 \mathrm{TD} \mathrm{MA}=11.6\end{array}$ & $\begin{array}{l}95.6 \\
91.7 \\
102.9 \\
103.8\end{array}$ & $\begin{array}{l}\text { Letter-Number test } \\
\text { (LNS) from } \\
\text { (WISC-IV) } \\
\text { Hopkins Verbal } \\
\text { Learning Test -Revised } \\
\text { (HVLT-R) }\end{array}$ & $\begin{array}{l}\text { Working } \\
\text { Memory } \\
\text { (WM), } \\
\text { Attention }\end{array}$ & $\begin{array}{l}\text { HFA+ more impaired than } \\
\text { HFA-, ADHD and TD on } \\
\text { verbal WM. HFA + and } \\
\text { ADHD more impaired } \\
\text { than TD, HFA- on delayed } \\
\text { recall }\end{array}$ & $\begin{array}{l}\text { Additive effect in HFA+. } \\
\text { Impaired delayed recall } \\
\text { deficit in HFA }+ \text { is related } \\
\text { to elevated attention } \\
\text { problems }\end{array}$ \\
\hline $\begin{array}{l}\text { Bühler et al. } \\
\text { (2011) }\end{array}$ & $\begin{array}{l}84 \mathrm{ADHD} \mathrm{MA}=9.7 \\
86 \mathrm{ASD} \mathrm{MA}=10.8 \\
\mathbf{5 2} \mathbf{A S D}+\mathbf{A D H D} \\
\mathrm{MA}=10.1\end{array}$ & $\begin{array}{l}97.9 \\
105.4 \\
99.0\end{array}$ & $\begin{array}{l}\text { Inhibition: TAP; } \\
\text { Go/Nogo (task of } \\
\text { selective attention) }\end{array}$ & Inhibition & $\begin{array}{l}\text { TAP: significant } \\
\text { difference between ASD } \\
\text { and ADHD. ASD+ and } \\
\text { ASD with a small to } \\
\text { medium effect size }\end{array}$ & $\begin{array}{l}\text { Significant difference in } \\
\text { inhibition between the } \\
\text { ASD and } \\
\text { ASD+ADHD }\end{array}$ \\
\hline $\begin{array}{l}\text { Chantiluke et al. } \\
\text { (2014) }\end{array}$ & $\begin{array}{l}18 \mathrm{ADHD} \mathrm{MA}=14.3 \\
15 \mathrm{ASD} \mathrm{MA}=14.3 \\
13 \mathrm{ASD}+\mathrm{MA}=14 \\
18 \mathrm{TD} \mathrm{MA}=15.2\end{array}$ & $\begin{array}{l}110 \\
112 \\
110.8 \\
120\end{array}$ & $\begin{array}{l}\text { Temporal discounting } \\
\text { fMRI task }\end{array}$ & Inhibition & $\begin{array}{l}\text { ASD + had the most } \\
\text { pronounced abnormalities } \\
\text { in their brain-behaviour } \\
\text { associations in key regions } \\
\text { of temporal discounting }\end{array}$ & $\begin{array}{l}\text { ASD }+ \text { is not simply a } \\
\text { phenocopy or an additive } \\
\text { combined pathology of } \\
\text { the two pure disorders }\end{array}$ \\
\hline $\begin{array}{l}\text { Dajani et al. } \\
(2016)\end{array}$ & $\begin{array}{l}93 \mathrm{ADHD} \mathrm{MA}=9.79 \\
30 \mathrm{ASD} \mathrm{MA}=9.76 \\
\mathbf{6 6} \mathrm{ASD}+\mathrm{MA}=10.4 \\
128 \mathrm{TD} \mathrm{MA}=10.0\end{array}$ & $\begin{array}{l}107.3 \\
106.1 \\
99.9 \\
115.7\end{array}$ & $\begin{array}{l}\text { BRIEF-P Rating Scale } \\
\text { NEPSY-II (Statue } \\
\text { subscale) } \\
\text { Backward Digit Span } \\
\text { (WISC) }\end{array}$ & $\begin{array}{l}\text { BRI-MI } \\
\text { Inhibition } \\
\text { WM }\end{array}$ & $\begin{array}{l}92 \% \text { of ASD + were in the } \\
\text { "impaired" class of EF. } \\
\text { The "impaired" class was } \\
\text { mainly composed of ASD } \\
+(45 \%)\end{array}$ & $\begin{array}{l}\text { ADHD symptoms in } \\
\text { ASD exacerbate ASD } \\
\text { symptomatology }\end{array}$ \\
\hline $\begin{array}{l}\text { Geurts et al. } \\
(2008)\end{array}$ & $\begin{array}{l}53 \mathrm{ADHD} \mathrm{MA}=9.1 \\
25 \mathrm{HFA} \mathrm{MA}=9.3 \\
\text { 32 } \mathrm{ASD}+\mathrm{MA}=8.6 \\
21 \mathrm{TS} \mathrm{MA}=10 \\
85 \mathrm{TD} \mathrm{MA}=9.2\end{array}$ & $\begin{array}{l}100.8 \\
106.8 \\
99.3 \\
102.1 \\
111.6\end{array}$ & $\begin{array}{l}\text { Simple two-choice RT } \\
\text { task were derived from } \\
\text { the Change Task }\end{array}$ & $\begin{array}{l}\text { Attention } \\
\text { problems }\end{array}$ & $\begin{array}{l}\text { 1-HFA and ASD + show } \\
\text { greater IIV compared to } \\
\text { the TD and the ADHD } \\
\text { groups, 2-HFA and ASD + } \\
\text { responded slower } \\
\text { compared to the ADHD } \\
\text { group }\end{array}$ & $\begin{array}{l}\text { Variability In ADHD is } \\
\text { associated with } \\
\text { comorbidity,RT } \\
\text { variability being specific } \\
\text { to ADHD is not } \\
\text { confirmed }\end{array}$ \\
\hline $\begin{array}{l}\text { Gomarus et al. } \\
(2009)\end{array}$ & $\begin{array}{l}15 \text { ADHD } \mathrm{MA}=9.8 \\
15 \text { PDD } \mathrm{MA}=10.2 \\
15 \text { PDDHD } \\
\mathrm{MA}=10.1 \\
15 \text { TD } \mathrm{MA}=10.1\end{array}$ & $\begin{array}{l}103.5 \\
108.6 \\
101.9 \\
107.1\end{array}$ & $\begin{array}{l}\text { Visual selective } \\
\text { memory search task. } \\
\text { Electro encephalogram } \\
\text { EEG (ERPs- } \\
\text { event-related } \\
\text { potentials) }\end{array}$ & $\begin{array}{l}\text { Selective } \\
\text { Attention } \\
\text { WM }\end{array}$ & $\begin{array}{l}\text { Clinical groups no differ } \\
\text { on reaction times or } \\
\text { number of omissions, and } \\
\text { no differences in the } \\
\text { number of false alarms. }\end{array}$ & $\begin{array}{l}\text { Less efficient } \\
\text { WM-functioning in all } \\
\text { clinical groups. Similar } \\
\text { performance in clinical } \\
\text { groups on WM, selective } \\
\text { attention. }\end{array}$ \\
\hline
\end{tabular}




\begin{tabular}{|c|c|c|c|c|c|c|}
\hline $\begin{array}{l}\text { Lundervold et } \\
\text { al. (2016) }\end{array}$ & $\begin{array}{l}38 \text { ADHD MA= } 10.0 \\
9 \text { ASD MA=10.3 } \\
\text { 11 ADHD+ASD } \\
\text { MA }=10.6 \\
134 \text { TD MA }=9.7\end{array}$ & $\begin{array}{l}78.1 \\
92.2 \\
87.1 \\
93.8\end{array}$ & $\begin{array}{l}\text { The Conners' } \\
\text { Continuous } \\
\text { Performance Test- } \\
\text { Second } \\
\text { Edition (CCPT-II) }\end{array}$ & Attention & $\begin{array}{l}\text { ADHD and ADHD+ did } \\
\text { less well than TD, ASD on } \\
\text { RT, accuracy, variability } \\
\text { and consistency }\end{array}$ & $\begin{array}{l}\text { ADHD + more similar to } \\
\text { ADHD than ASD on } \\
\text { CCPT } \\
\text { Authors suggest } \\
\text { phenotypic overlap } \\
\text { between ASD, ADHD }\end{array}$ \\
\hline $\begin{array}{l}\text { Neely et al. } \\
(2016)\end{array}$ & $\begin{array}{l}75 \text { ADHD MA=7.2 } \\
\mathbf{2 5} \text { ADHD+ASD } \\
\text { MA=7.5 } \\
123 \mathrm{TD} \mathrm{MA}=7.3\end{array}$ & $\begin{array}{l}- \\
- \\
-\end{array}$ & $\begin{array}{l}\text { Digit Span Backward } \\
\text { Matrix Reasoning } \\
\text { (WASI) } \\
\text { Test of Everyday } \\
\text { Attention for Children } \\
\text { (TEA-Ch) }\end{array}$ & $\begin{array}{l}\text { WM } \\
\text { Inhibition }\end{array}$ & $\begin{array}{l}\text { ADHD+ASD did not } \\
\text { differ from ADHD on EF } \\
\text { tasks. Greater ASD or } \\
\text { inattention were } \\
\text { associated with poorer } \\
\text { reasoning and inhibition. }\end{array}$ & $\begin{array}{l}\text { Children with } \\
\text { ADHD+ASD are likely } \\
\text { to demonstrate the EF } \\
\text { deficits associated with } \\
\text { ADHD alone }\end{array}$ \\
\hline $\begin{array}{l}\text { Pitzianti et al. } \\
\text { (2016) }\end{array}$ & $\begin{array}{l}13 \text { ADHD MA=10.1 } \\
13 \text { HFA MA=10.6 } \\
12 \text { ADHD+HFA } \\
10.2 \\
13 \text { TD MA= } 11\end{array}$ & $\begin{array}{l}97.4 \\
106 \\
108 \\
106\end{array}$ & $\begin{array}{l}\text { Planning: Tower of } \\
\text { London } \\
\text { Verbal WM: Backward } \\
\text { digit span; Response } \\
\text { Inhibition: } \\
\text { Go/ noGo Task }\end{array}$ & $\begin{array}{l}\text { Planning } \\
\text { WM } \\
\text { Inhibition }\end{array}$ & $\begin{array}{l}\text { Planning difficulties more } \\
\text { serious in ADHD+HFA } \\
\text { compared with ADHD, } \\
\text { HFA; WM: ADHD+=TD } \\
\text { Inhibition: no differences } \\
\text { clinical groups }\end{array}$ & $\begin{array}{l}\text { The ADHD+HFA was } \\
\text { impaired on measures of } \\
\text { planning and } \\
\text { response inhibition when } \\
\text { compared with TD }\end{array}$ \\
\hline $\begin{array}{l}\text { Sinzig et al. } \\
(2008 \mathrm{a})\end{array}$ & $\begin{array}{l}30 \text { ADHD MA=12.9 } \\
20 \text { ASD- MA=14.5 } \\
21 \text { ASD+ MA=10.7 } \\
30 \text { TD MA=12.8 }\end{array}$ & $\begin{array}{l}102 \\
112 \\
103 \\
109\end{array}$ & $\begin{array}{l}\text { Inhibition Go/NoGo, } \\
\text { Sustained, divided } \\
\text { Attention, Alertness: } \\
\text { Test for Attentional } \\
\text { performance }\end{array}$ & $\begin{array}{l}\text { Inhibition } \\
\text { Attention }\end{array}$ & $\begin{array}{l}\text { Inhibition: no differences } \\
\text { between TD and clinical } \\
\text { groups, ADHD }<\text { TD on } \\
\text { sustained and divided } \\
\text { attention. ASD+ difficult } \\
\text { on divided attention and } \\
\text { alertness. }\end{array}$ & $\begin{array}{l}\text { There was no evidence } \\
\text { that ASD+ have a } \\
\text { specific profile in } \\
\text { comparison to pure ASD }\end{array}$ \\
\hline $\begin{array}{l}\text { Sinzig et al. } \\
(2008 b)\end{array}$ & $\begin{array}{l}20 \mathrm{ADHD} \mathrm{MA}=12.2 \\
20 \mathrm{ASD}-\mathrm{MA}=14.3 \\
\mathbf{2 0} \mathrm{ASD}+\mathrm{MA}=10.9 \\
20 \mathrm{TD} \mathrm{MA}=13.1\end{array}$ & $\begin{array}{l}98 \\
112 \\
103 \\
113\end{array}$ & $\begin{array}{l}\text { Inhibition: (TAP); } \\
\text { Flexibility, WM, } \\
\text { planning: Cambridge } \\
\text { Neuropsychological } \\
\text { Automated Test } \\
\text { Battery }\end{array}$ & $\begin{array}{l}\text { Inhibition } \\
\text { Flexibility } \\
\text { Planning } \\
\text { WM }\end{array}$ & $\begin{array}{l}\text { Inhibition: ASD+ worse } \\
\text { than the TD and ASD. } \\
\text { Flexibility: more difficult } \\
\text { for ASD+. ASD+ } \\
\text { significant correlations } \\
\text { flexibility with inattention } \\
\text { and stereotype behavior }\end{array}$ & $\begin{array}{l}\text { ASD + showed } \\
\text { similarities to ADHD } \\
\text { with inhibitory but not to } \\
\text { WM deficits. }\end{array}$ \\
\hline $\begin{array}{l}\text { Takeuchi et al. } \\
\text { (2013) }\end{array}$ & $\begin{array}{l}20 \text { ADHD MA=10.3 } \\
8 \text { PDD- MA=11.2 } \\
\mathbf{1 6} \text { PDD+ MA=9.7 } \\
60 \text { TD MA }=10.1\end{array}$ & $\begin{array}{l}98.7 \\
95.0 \\
93.9 \\
-\end{array}$ & $\begin{array}{l}\text { Inhibition, WM: } \\
\text { E-prime } \\
\text { neuropsychological } \\
\text { software }\end{array}$ & $\begin{array}{l}\text { Inhibition } \\
\text { WM }\end{array}$ & $\begin{array}{l}\mathrm{ADHD} \text { and } \mathrm{PDD}+\text { worse } \\
\text { on verbal WM and } \\
\text { response variability. } \\
\text { Impairments in inhibition } \\
\text { in } 3 \text { clinical groups. }\end{array}$ & $\begin{array}{l}\text { PDD+ is not a simple } \\
\text { combination of ADHD } \\
\text { and PDD in terms of } \\
\text { cognitive functions. }\end{array}$ \\
\hline Tye el al. (2014) & $\begin{array}{l}18 \text { ADHD MA=10.4 } \\
19 \text { ASD MA=11.6 } \\
29 \text { ASD+ MA= } 10.5 \\
26 \text { TD MA }=10.5\end{array}$ & $\begin{array}{l}104.1 \\
115.6 \\
109.7 \\
120.0\end{array}$ & $\begin{array}{l}\text { Event related } \\
\text { potencials (ERPs) were } \\
\text { recorded during a } \\
\text { flankered } \\
\text { cued-continuous } \\
\text { performance test } \\
(\text { CPT-OX) }\end{array}$ & $\begin{array}{l}\text { Attention } \\
\text { Inhibition }\end{array}$ & $\begin{array}{l}\text { ADHD and ASD+ made } \\
\text { more omission errors and } \\
\text { had increased } \\
\text { reaction-time (RT) } \\
\text { variability compared to } \\
\text { TD/ASD. ASD and ASD+ } \\
\text { showed reduced N2 } \\
\text { compared to TD/ADHD }\end{array}$ & $\begin{array}{l}\text { Conceptualization of the } \\
\text { co-morbid condition as a } \\
\text { distinct condition }\end{array}$ \\
\hline $\begin{array}{l}\text { Unterrainer et } \\
\text { al. (2016) }\end{array}$ & $\begin{array}{l}42 \text { ADHD MA=9.83 } \\
18 \text { ASD MA=10.14 } \\
23 \text { ASD+ MA=10.17 } \\
42 \text { TD MA=9.76 }\end{array}$ & $\begin{array}{l}94.4 \\
97.0 \\
98.8 \\
97.5\end{array}$ & The Tower of London & Planning & $\begin{array}{l}\text { ASD + showed the lowest } \\
\text { accuracy in younger } \\
\text { children, but similar } \\
\text { performance as TD at } \\
\text { older ages, suggesting } \\
\text { delayed development. }\end{array}$ & $\begin{array}{l}\text { ADHD and ASD+ } \\
\text { showed no deficit } \\
\text { in planning, caused by } \\
\text { ADHD symptoms }\end{array}$ \\
\hline
\end{tabular}




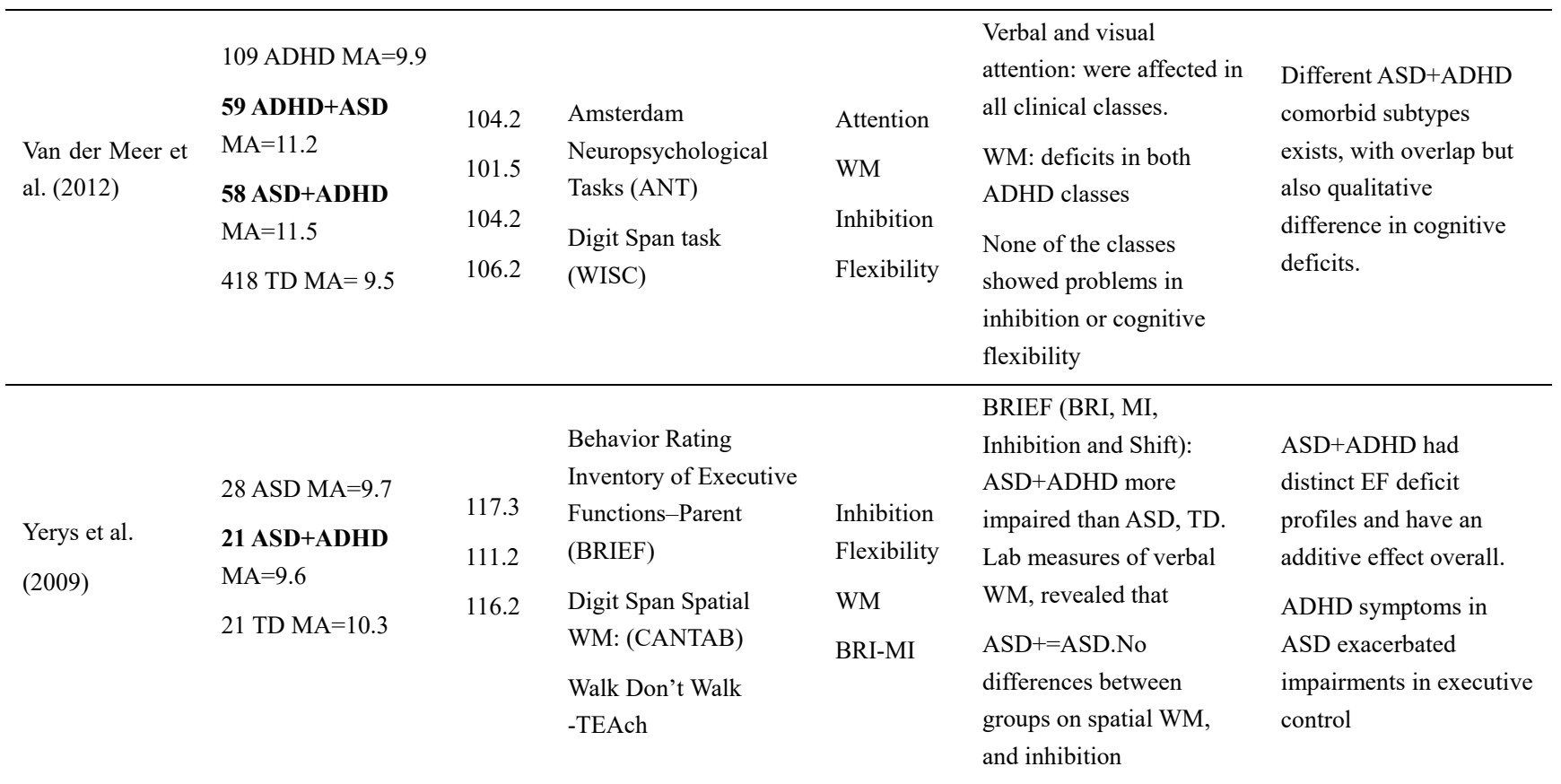

Note. MA (Mean age), ADHD (Attention deficit hyperactivity disorder), ASD (Autism spectrum disorder), TD (Typical developmental), ASD+ (Autism spectrum disorder + Attention deficit hyperactivity disorder), PDD (Pervasive developmental disorder), BRI (Behavioral regulation index), MI (Metacognitive index), PDDHD (Pervasive developmental disorder and hyperactivity disorder), HFA (High functioning autism), TS (Tourette Syndrome), RT-ISV (Reaction time intra subject variability), fMRI (functional magnetic resonance imaging), WM (Working memory), TAP (Test battery for attention performance).

\subsection{Characteristics of Included Studies}

All studies involved participants with comorbid group; specifically 15 studies included children and adolescents with ASD, high functioning autism (HFA), or pervasive developmental disorder (PDD) and comorbid ADHD clinical symptoms (ASD+ADHD) and three studies included children and adolescents with ADHD and comorbid autism clinical symptoms (ADHD+ASD), one of them included both comorbid conditions. There were 753 individuals with ADHD, 357 were individuals with ASD or PDD, 410 were ASD+ADHD, 96 were ADHD+ASD and 1.219 were typically developing individuals (TD). The participants were mostly male. Only $1 / 17$ studies had not TD group and 3/17 had not ASD or ADHD group. The age of the children ranged from 6 years to 18 years, except one study which reported a range age for ADHD group from 4.5 to 22 years. All of the studies included children with IQ $>78$ (table 1). Assessment of EF has been based largely on laboratory neuropsychological measures such as computerized cognitive tests, and performance-based tests. Furthermore two and one study reported data from event-related potentials (ERP) and functional magnetic resonance imaging (fMRI) respectively. Only 2 studies included parents' reports as the Behavior rating inventory of executive function (BRIEF) measuring EFs in children. Table 1 reports the measures used in the studies included in this review. The domains of executive functions analyzed in the studies included in the present review were as follows: attention, response inhibition, working memory (WM), planning, and flexibility. Eight studies examined different domains of attention problems, ten studies examined response inhibition, eight studies examined working memory, three studies examined planning, three studies examined flexibility and only one study examined a wide range of EF domains.

\subsection{Attention}

With regard to attention all included studies found more impairments in attention capabilities in comorbid ASD+ADHD or ADHD+ASD groups compared to TD children. Gomarus, Wijers, Minderaa and Althaus (2009) found no significant differences between the ASD+ADHD and both ASD, ADHD on selective attention. Five studies demonstrated that ASD+ADHD and ADHD groups tend to have more attention problems compared to the ASD group (Adamo et al., 2014; Andersen, Hovik, Skogli, Egeland, \& Øie, 2013; Sinzig, Bruning, Morsch, \& Lehmkuhl, 2008a; Lundervold et al., 2016; Tye et al., 2014). Additionally only one study found that ASD+ADHD and ASD groups tend to have more attention problems compared to the ADHD group (Geurts et al., 2008). Finally one study showed that ADHD+ASD group performed worse than ADHD group (Van der Meer et al., 2012). 
Gomarus et al. (2009) examined the processes of selective attention in children with ADHD, ASD with or without hyperactivity clinical symptoms and TD with event-related potentials. No distinction between the clinical groups could be observed with respect to performance or ERP measures of selective attention. Tye et al. (2014) examined in an event-related potential study attention problems and inhibition using a flanker cued continuous performance test (CPT Flanker) in a neurophysiological study. Children with ASD+ADHD and ADHD showed more omission errors and had greater reaction time variability. Results suggested that children with ASD+ADHD had an "additive" profile rather having a qualitatively distinct distinctive pattern of deficits. Similarly, Lundervold et al. (2016) found that the ASD+ADHD group had a higher variability. Adamo et al. (2014) assessed the influence of comorbidity on response time intra-subject variability (RT-ISV), in children with ASD, ASD+ADHD, ADHD and TD using a sustained attention task. Authors revealed shared abnormalities between ADHD and ASD+ADHD. Andersen et al. (2013) evaluated acquisition and delayed recall in 38 high functioning autism children-HFA (age 8-17) dividing the HFA group into children with (HFA+) or without (HFA-) "attention problems" according to the Child Behaviour Checklist. HFA+ADHD and ADHD groups showed impaired delayed recall deficit which are related with attention problems. Sinzig et al. (2008a) assessed sustained and divided attention and alertness in children (6-18) with ADHD, ASD with or without comorbid ADHD and TD. Results demonstrated that the ASD+ADHD group had more false alarms on the alertness task. Authors concluded that it is not yet clear if children with ASD and comorbid ADHD symptoms have a specific profile. The study of Van der Meer et al. (2012) showed that the ADHD+ASD class performed worse than TD and ADHD groups on visuospatial task. Geurts et al. (2008) evidenced high ISV in children with ASD and/or ASD + ADHD and no differences between children with ADHD and TD on any of the RT indices. Authors suggest that RT variability in ADHD may be "overstated".

\subsection{Response Inhibition}

Comparing EF performance between ASD, ADHD, ASD+ADHD and TD groups, three studies detected no statistical significant differences in inhibition response between ASD, ADHD and comorbid groups compared to the TD group (Sinzig et al., 2008a; Van der Meer et al., 2012; Yerys et al., 2009). No significant differences between clinical groups on inhibit performances were found in three studies (Neely, Green, Sciberras, Hazell, \& Anderson, 2016; Pitzianti et al., 2016; Takeuchi et al., 2013). In three studies, ADHD and ASD+ADHD patients demonstrated more impairment in inhibitory control compared to the ASD patients (Bühler et al., 2011; Sinzig, Morsch, Bruning, Schmidt, \& Lehmkuhl, 2008b; Tye et al., 2014). In one study, the ASD+ADHD group had more deficits on inhibition compared to other groups (Chantiluke et al., 2014). Sinzig et al. (2008a) used a Go/NoGo task. No significant inhibition deficits were observed in any group. Furthermore in the comorbid group results demonstrated associations between inattention symptoms and inhibition response. However the results suggest that there aren't evidence that ASD+ADHD group has a specific EF profile in comparison to ASD only.

Similarly Van der Meer et al. (2012) did not identify deficits with inhibition in their participants using an inhibition task. Authors discuss the influence of the predictable nature of the task. In their study, Yerys et al. (2009) compared cognitive and behavioral profiles in children with ASD, ASD+ADHD and TD. Pre-potent response inhibition was assessed by Walk Don't Walk-Test of Everyday Attention for Children. Parent rating scale demonstrated decreased inhibition functioning in children with ASD and ASD+ADHD compared with TD children. The study of Neely et al. (2016) assessed by Walk Don't Walk-Test of Everyday Attention for Children response inhibition in children with ADHD, ADHD+ASD and TD. There were no significant differences between children with ADHD and $\mathrm{ADHD}+\mathrm{ASD}$ on any EF tasks. However the comorbid group performed significantly worse than the control group. Similarly Pitzianti et al. (2016) found the ADHD+HFA was impaired on response inhibition when compared with the TD group using a computerized task of Go/No-Go. Takeuchi et al. (2013) conducted research on inhibitory function and working memory in ADHD, pervasive developmental disorder (PDD), PDD+ADHD and TD using two measures of response inhibition. They noted a lack of significant differences between clinical groups using the Go/No-Go task. Bühler et al. (2011) and Sinzig et al. (2008b) assessed prepotent response using the Test for Attentional performance (TAP Go/No-Go condition). They found that the ASD+ADHD group was more impaired that the other clinical groups. Sinzig et al. (2008a) using the same task and the same sample as Sinzig et al. (2008b) did not find significant differences between all groups. Tye et al. (2014) using a CPT Flanker task found that both ADHD groups showed abnormal inhibitory processing. Authors suggest an additive model of ASD+ADHD. A fMRI study conducted by Chantiluke et al. (2014) compared the comorbid group (ASD+ADHD) and ADHD, ASD only disorders using a temporal discounting task. Results indicated that the comorbid group had abnormalities in key regions of temporal discounting.

\subsection{Working Memory}

Both verbal memory and visuospatial memory were investigated in 3/8 studies (Takeuchi et al., 2013; Van der 
Meer et al., 2012; Yerys et al., 2009). The five studies which assessed spatial working memory (SWM) failed to find spatial working memory deficits in children with ASD and comorbid ADHD (Gomarus et al., 2009; Sinzig et al., 2008b; Takeuchi et al., 2013; Van der Meer et al., 2012; Yerys et al., 2009). Two studies used the Cambridge Neuropsychological Automated Test Battery (CANTAB). However, one study reported significant difficulties on spatial working memory in children with ADHD with comorbid ASD clinical symptoms compared to TD group (Van der Meer et al., 2012). Verbal working memory (VWM) was assessed in six studies. Three studies demonstrated that VWM was impaired in children with ASD+ADHD when compared with the TD group (Andersen et al., 2013; Takeuchi et al., 2013; Yerys et al., 2009). Two studies reported VWM deficits in children with ADHD+ASD (Neely et al., 2016; Van der Meer et al., 2012). One study indicated VWM with no impairment in ADHD+ASD group (Pitzianti et al., 2016) and one study found that children with ASD+ADHD did not differ from the other groups regarding both SWM and VWM (Van der Meer et al., 2012). The study of Andersen et al. (2013) assessed Verbal working memory using a letter/number sequencing task. Children with both ASD and ADHD showed significant impairments when compared with ADHD, ASD and TD groups. The authors concluded that ASD+ADHD symptoms represent an "additive" effect in which ADHD symptoms impact negatively in ASD. Recently Neely et al. (2016) and Pitzianti et al. (2016) evaluated verbal working memory using the Backward Digit Span. Neely et al. (2016) found a similar EF profile between ADHD+ASD and ADHD groups, while Pitzianti et al. (2016) found similar EF profile between ADHD+ASD and ASD groups. Gomarus et al. (2009) carried out a visual memory search task. The results did not demonstrate a significant differences between clinical groups in either, performance data or electroencephalography (EEG) data. The authors suggested that the demands of the task were not high enough to show group differences. Sinzig et al. (2008b) reported similarities between ASD+ADHD and ASD with regard to spatial working memory deficit. Authors discussed that comorbid ADHD symptoms don't seem to play the key role in working memory. Yerys et al. (2009) didn't find significant differences between both ASD groups and TD children in SWM performance. However their study demonstrated that the ASD+ADHD group scored significantly lower than TD children, and similar to ASD group. The results are in contrast with previous study (Gomarus at al., 2009), probably because of differences in task design. Takeuchi et al. (2013) examined both VWM and SWM. Results found more impairments in children with ADHD and ASD+ADHD in VWM and a relationship between ADHD symptoms (inattention) and deficits of VWM. Similarly, Van der Meer et al. (2012) found that ADHD symptoms associated with VWM deficits and ASD+ADHD formed "an intermediate group" similar to the other clinical groups regarding WM.

\subsection{Planning}

Three studies evaluated planning deficits using Tower of London (ToL) task with mixed results. Sinzig et al. (2008b) using a computerized test of spatial planning based upon the ToL found a trend toward longer planning times in ASD children without ADHD compared to children with ADHD only and TD group. ASD+ADHD group had a longer test duration than TD group $(\mathrm{d}=0.6)$. However there were no significant differences for any of the tasks impeding strong conclusion in part because of differences in IQ and age between groups. Pitzianti et al. (2016) found that planning difficulties were more serious in the ADHD+ASD group when compared with the other clinical groups. Specifically, results indicated significant differences between clinical groups and the control group in ToL total scores and ToL total time. Significant differences were also found between the ADHD group and the HFA group in ToL total time but not in ToL total scores, between the ADHD group and the comorbid ADHD+HFA group in ToL total time but not in ToL total scores, and between the HFA group and the comorbid ADHD+HFA group in ToL total scores but not in ToL total time. Unterrainer et al. (2016) investigated planning in 83 children with ASD, ADHD, ASD+ADHD, and typically developing children using the ToL. Results found children with ASD + ADHD were more impaired and less accurate at younger ages but comparable to other groups at older ages. Authors suggests a developmental delay that is more robust in the ASD+ADHD group.

\subsection{Flexibility}

Flexibility involves transitioning from one thought to another, shifting successfully from one task to another, and using flexible problem solving in a variety of contexts (Lawson et al., 2015). Three studies evaluated flexibility problems (Sinzig et al., 2008b; Van der Meer et al., 2012; Yerys et al., 2009). Sinzig et al. (2008b) assessed the ability to attend to specific attributes of stimuli, shifting attention from one attribute to another when required using an intra dimensional/extra dimensional shift task. Results showed no statistically significant differences between any of the groups. Although, there were more difficulties in comorbid group (ASD+ADHD). They made more errors and needed more time for the task compared to the ASD group and TD group, but completed more stages than TD children. Authors suggested that one of the reasons might be the high proportion of children with Asperger syndrome in the sample. Similar results found Van der Meer et al. (2012) using a cognitive flexibility task from the ANT program. The tasks was used for assessed Inhibition and flexibility. Non of the groups showed 
problems in cognitive flexibility. Authors suggested that one reason might be the predictable nature of the task. Conversely, Yerys et al. (2009) reported that the ASD+ADHD group was more impaired than ASD and TD groups on the Behavior rating inventory of executive function (BRIEF).

\subsection{EF Profiles}

Analyzing a wide range of EF domains, Dajani, Llabre, Nebel, Mostofsky and Uddin (2016) identified distinct profiles of EF across ADHD, ASD, ASD+ADHD and TD children using a latent profile analysis with indicators of EF. The EF was examined using The Behavior Rating Inventory of Executive Function (BRIEF-parent form) and neuropsychological measures such as "statue subtest" (inhibit responses) from The Developmental Neuropsychological Assessment (NEPSY-II) and backward digit span test (working memory). The results pointed that $92 \%$ of children in the ASD+ADHD group were in the "impaired EF class". In comparison, only $47 \%$ of children with ASD and $63 \%$ of children with ADHD were in the "impaired class". Authors discuss the need to take ADHD and ASD symptomatology into account when assessing EF abilities in children.

\section{Discussion}

The main research aim of this study is to provide an update on the executive functions in ASD and ADHD comorbidity. Findings presented provide evidence for executive dysfunctions across different key components (Attention, response inhibition, working memory, planning and flexibility) in children and adolescents with ASD and comorbid ADHD clinical symptoms.

Most of the studies reported that attention deficits are more severe in children with ASD+ADHD and children with ADHD than children with ASD and typical developing. Moreover, examining different attentional constructs, children with ASD+ADHD differed from TD children especially on sustained attention and alertness (Adamo et al., 2014; Andersen et al., 2013; Sinzig et al., 2008a; Lundervold et al., 2016; Tye et al., 2014). Some studies evidence that the comorbid group is the group with the most pronounced brain function abnormalities (Chantiluke et al., 2014) and more impaired on daily-life executive functioning (Dajani et al., 2016). Similarly, studies that had focused on response inhibition report that ADHD and ASD+ADHD patients show more dysfunction on inhibitory control compared to the ASD patients (Bühler et al., 2011; Sinzig et al., 2008b; Tye et al., 2014). In addition, even studies that do not find differences between the clinical groups on response inhibition suggest a tendency of decreased performance in the comorbid group (Neely et al., 2016; Pitzianti et al., 2016; Takeuchi et al., 2013). In contrast few studies show no differences between control group and clinical groups (Sinzig et al., 2008a, but see Sinzig et al. (2008b); Van der Meer et al., 2012; Yerys et al., 2009), but results from BRIEF show a worse inhibition functioning in children with ASD and ASD+ADHD compared with TD children. Additionally, findings from literature review evidence more deficits in children with ASD+ADHD on verbal working memory than spatial working memory, that seem to be intact.

Moreover, some studies report children with ADHD+ASD or ASD+ADHD demonstrate similar deficits to ADHD in spatial working memory and verbal working memory. In contrast, others have found children with ADHD+ASD do not differ from typically developing children on spatial working memory or verbal working memory. Few studies have focus on planning and flexibility EF domains comparing a comorbid group (ASD+ADHD or ADHD+ASD) with TD, ADHD, ASD groups. Only two studies report inferior performance in the comorbid group compared with TD group on planning tasks (Pitzianti et al., 2016; Unterrainer et al., 2016). On the other hand three studies analyzed the flexibility domain. Only one study found shift impairments in children with ASD+ADHD compared to TD and the other clinical groups using the BRIEF (Yerys et al., 2009). The current studies of EF in children with ASD+ADHD or ADHD+ASD are limited by the small sample of subjects tending to be biased towards males, and cross-sectional designs which constrains the interpretation of findings. Additionally, some studies span broad age ranges, including children aged 6 years to adults of $18 / 22$ years, comprising multiple critical periods for EF development. Finally, with regard to measurement, the wide range of tools employed across studies limits the generalization of results.

This review highlights the fact that performance in neuropsychological tests may not reveal differences in the neurocognitive processes underlying the clinical diagnosis. It would be useful to combine neuropsychological test of EF with ecologically valid parent/self-report measures of EF, which would provide a more comprehensive evaluation of EF domains in a less structured setting. Moreover, cognitive science literature suggests that performance-based and rating measures of executive function capture different cognitive levels of analysis groups (see review of Toplak, West, \& Stanovich, 2013).

\section{Conclusion}

In summary, results suggest that a possible differentiation in EF profile between comorbid group and ADHD or 
ASD is hard to find and it's an open question to future research. Although it is not possible to extract strong evidence for the EF profiles in ASD+ADHD comorbid group, studies supports the notion that children and adolescents with ASD and ADHD often shows overlap with some clinical symptoms of ASD and ADHD. However the question of whether combined ASD and ADHD symptoms represents a distinct phenotype or merely overlapping phenotypes remains still unclear. This may agree with clinical practice, where differential diagnosis is a subject of discussion (Antshel, Zhang-James, Wagner, Ledesma, \& Faraone, 2016). The findings of this review have implications for educational practice, alerting professionals of the need to include EF in the evaluation process of EF deficits in ASD and comorbid ADHD children. It is a relevant because children with differing EF profiles will likely respond differently to interventions. EF influences the sociopersonal adaptation throughout the life cycle and has been shown that with the training they improve the academic and social skills.

Because executive dysfunction is a central limitation in ADHD, there have been several studies that have been proposed to analyze the effects of cognitive training with promising results (see meta-analysis by Cortese et al., 2015). In ASD, the studies that have studied the repercussions of cognitive training are more scarce. For example, it has been found that the estimates of parents and teachers of change and planning/organization of the BRIEF are normalized with the implementation of a cognitive-behavioral intervention in the school, which focused on flexibility and planning (Kenworthy et al., 2014). In the same line, very promising results have been reported, emotional control, working memory, planning and monitoring with children with high functioning autism with a program in the school for the development of social competence in adolescents (Stichter, Herzog, Owens, \& Malugen, 2016). To our knowledge the only work that has studied the impact of executive function training on ASD+ADHD found improvement in attention, impulsivity sympstoms and academic achievement in children and adolescents with ASD and comorbid ADHD (Weckstein, Weckstein, Parker, \& Westerman, 2017).

Further studies should provide a broader insight about underlying EF profile associated with both ASD and ADHD which help to design more personalized treatment approach.

\section{Declaration of Conflicting Interests}

The author(s) declared no potential conflicts of interest with respect to the research, authorship, and/or publication of this article.

\section{Funding}

This study was supported by predoctoral fellowship UNIVERSITY OF VALENCIA-INV-PREDOC15-265889.

\section{References}

Adamo, N., Huo, L., Adelsberg, S., Petkova, E., Castellanos, F. X., \& Di Martino, A. (2014). Response time intra-subject variability: commonalities between children with autism spectrum disorders and children with ADHD. European Child \& Adolescent Psychiatry, 23, 69-79. https://doi.org/10.1007/s00787-013-0428-4.

American Psychiatric Association. (2013). Diagnostic and statistical manual of mental disorders (5th ed.). Arlington: Author.

Andersen, P. N., Hovik, K. T., Skogli, E. W., Egeland, J., \& Øie, M. (2013). Symptoms of ADHD in children with high-functioning autism are related to impaired verbal working memory and verbal delayed recall. PloS One, 8, e64842. https://doi.org/10.1371/journal.pone.0064842

Antshel, K. M., Zhang-James, Y., Wagner, K. E., Ledesma, A., \& Faraone, S. V. (2016). An update on the comorbidity of ADHD and ASD: A focus on clinical management. Expert Review of Neurotherapeutics, 16, 279-293. https://doi.org/10.1586/14737175.2016.1146591

Bühler, E., Bachmann, C., Goyert, H., Heinzel-Gutenbrunner, M., \& Kamp-Becker, I. (2011). Differential diagnosis of autism spectrum disorder and attention deficit hyperactivity disorder by means of inhibitory control and 'theory of mind'. Journal of Autism and Developmental Disorders, 41, 1718-1726. https://doi.org/10.1007/s10803-011-1205-1

Corbett, B. A., Constantine, L. J., Hendren, R., Rocke, D., \& Ozonoff, S. (2009). Examining executive functioning in children with autism spectrum disorder, attention deficit hyperactivity disorder and typical development. Psychiatric Research, 166, 210-222. https://doi.org/10.1016/j.psychres.2008.02.005

Cortese, S., Ferrin, M., Brandeis, D., Buitelaar, J., Daley, D., Dittmann, R. W., ... \& Zuddas, A. (2015). Cognitive training for attention-deficit/hyperactivity disorder: meta-analysis of clinical and neuropsychological outcomes from randomized controlled trials. Journal of the American Academy of Child \& Adolescent Psychiatry, 54, 164-174. https://doi.org/10.1016/j.jaac.2014.12.010 
Craig, F., Margari, F., Legrottaglie, A. R., Palumbi, R., de Giambattista, C., \& Margari, L. (2016). A review of executive function deficits in autism spectrum disorder and attention-deficit/hyperactivity disorder. Neuropsychiatric Disease and Treatment, 12, 1191. https://doi.org/10.2147/NDT.S104620

Chantiluke, K., Christakou, A., Murphy, C. M., Giampietro, V., Daly, E. M., Ecker, C., ... \& MRC AIMS Consortium. (2014). Disorder-specific functional abnormalities during temporal discounting in youth with Attention Deficit Hyperactivity Disorder (ADHD), Autism and comorbid ADHD and Autism. Psychiatry Research: Neuroimaging, 223, 113-120. https://doi.org/10.1016/j.pscychresns.2014.04.006

Dajani, D. R., Llabre, M. M., Nebel, M. B., Mostofsky, S. H., \& Uddin, L. Q. (2016). Heterogeneity of executive functions among comorbid neurodevelopmental disorders. Scientific Reports, 6, 36566. https://doi.org/10.1038/srep36566.

Diamond, A. (2013). Executive functions. Annual Review of Psychology, 64, 135-168.

Elsabbagh, M., Divan, G., Koh, Y. J., Kim, Y. S., Kauchali, S., Marcín, C., ... \& Yasamy, M. T. (2012). Global prevalence of autism and other pervasive developmental disorders. Autism Research, 5, 160-179. https://doi.org/10.1002/aur.239

Geurts, H. M., Grasman, R. P., Verté, S., Oosterlaan, J., Roeyers, H., van Kammen, S. M., \& Sergeant, J. A. (2008). Intra-individual variability in ADHD, autism spectrum disorders and Tourette's syndrome. Neuropsychologia, 46, 3030-3041. https://doi.org/10.1016/j.neuropsychologia.2008.06.013.

Gjevik, E., Eldevik, S., Fjæran-Granum, T., \& Sponheim, E. (2011). Kiddie-SADS reveals high rates of DSM-IV disorders in children and adolescents with autism spectrum disorders. Journal of Autism and Developmental Disorders, 41, 761-769. https://doi.org/10.1007/s10803-010-1095-7

Goldberg, M. C., Mostofsky, S. H., Cutting, L. E., Mahone, E. M., Astor, B. C., Denckla, M. B., \& Landa, R. J. (2005). Subtle executive impairment in children with autism and children with ADHD. Journal of Autism and Developmental Disorders, 35, 279-293.

Goldstein, S., \& Naglieri, J. A. (Eds.). (2013). Handbook of executive functioning. New York: Springer Science \& Business Media.

Gomarus, H. K., Wijers, A. A., Minderaa, R. B., \& Althaus, M. (2009). ERP correlates of selective attention and working memory capacities in children with ADHD and/or PDD-NOS. Clinical Neurophysiology, 120, 60-72. https://doi.org/10.1016/j.clinph.2008.10.018

Happé, F., \& Ronald, A. (2008). The 'fractionable autism triad': a review of evidence from behavioural, genetic, cognitive and neural research. Neuropsychology Review, 18, 287-304. https://doi.org/10.1007/s11065-008-9076-8

Hartman, C. A., Geurts, H. M., Franke, B., Buitelaar, J. K., \& Rommelse, N. N. (2016). Changing ASD-ADHD symptom co-occurrence across the lifespan with adolescence as crucial time window: Illustrating the need to go beyond childhood. Neuroscience \& Biobehavioral Reviews, 71, 529-541. https://doi.org/10.1016/j.neubiorev.2016.09.003

Hill, E. L. (2004). Evaluating the theory of EF deficits in autism. Developmental Review, 24, 189-233.

Johnson, M. H., Gliga, T., Jones, E., \& Charman, T. (2015). Annual Research Review: Infant development, autism, and ADHD-early pathways to emerging disorders. Journal of Child Psychology and Psychiatry, 56, 228-247. https://doi.org/10.1111/jcpp.12328

Kaat, A. J., Gadow, K. D., \& Lecavalier, L. (2013). Psychiatric symptom impairment in children with autism spectrum disorders. Journal of Abnormal child Psychology, 41, 959-969. https://doi.org/10.1007/s10802-013-9739-7.

Kenworthy, L., Anthony, L. G., Naiman, D.Q., Cannon, L., Wills, M. C., Luong-Tran, C., .. Wallace, G. L. (2014). Randomized controlled effectiveness trial of executive function intervention for children on the autism spectrum. Journal of Child Psychology and Psychiatry, 55, 374-383. https://doi.org/10.1111/jcpp.12161

Kotte, A., Joshi, G., Fried, R., Uchida, M., Spencer, A., Woodworth, K. Y., ... \& Biederman, J. (2013). Autistic traits in children with and without ADHD. Pediatrics, 132, e612-e622. https://doi.org/10.1542/peds.2012-3947

Lai, C. L. E., Lau, Z., Lui, S. S., Lok, E., Tam, V., Chan, Q., ... \& Cheung, E. F. (2017). Meta-analysis of neuropsychological measures of executive functioning in children and adolescents with high-functioning 
autism spectrum disorder. Autism Research, 10, 911-939. https://doi.org/10.1002/aur.1723

Lawson, R. A., Papadakis, A. A., Higginson, C. I., Barnett, J. E., Wills, M. C., Strang, J. F., ... \& Kenworthy, L. (2015). Everyday executive function impairments predict comorbid psychopathology in autism spectrum and attention deficit hyperactivity disorders. Neuropsychology, 29, 445-453. https://doi.org/10.1037/neu0000145

Leitner, Y. (2014). The co-occurrence of autism and attention deficit hyperactivity disorder in children - what do we know? Frontiers in Human Neuroscience, 8, 268. https://doi.org/10.3389/fnhum.2014.00268

Lundervold, A. J., Stickert, M., Hysing, M., Sørensen, L., Gillberg, C., \& Posserud, M. B. (2016). Attention deficits in children with combined autism and ADHD: a CPT study. Journal of Attention Disorders, 20, 599-609. https://doi.org/10.1177/1087054712453168

Mattila, M. L., Hurtig, T., Haapsamo, H., Jussila, K., Kuusikko-Gauffin, S., Kielinen, M., ... \& Pauls, D. L. (2010). Comorbid psychiatric disorders associated with Asperger syndrome/high-functioning autism: A community-and clinic-based study. Journal of Autism and Developmental Disorders, 40, 1080-1093. https://doi.org/10.1007/s10803-010-0958-2.

Moher, D., Liberati, A., Tetzlaff, J., Altman, D. G., \& Prisma Group. (2009). Preferred reporting items for systematic reviews and meta-analyses: the PRISMA statement. PLoS Medicine, 6(7), e1000097.

Neely, R. J., Green, J. L., Sciberras, E., Hazell, P., \& Anderson, V. (2016). Relationship Between Executive Functioning and Symptoms of Attention-Deficit/Hyperactivity Disorder and Autism Spectrum Disorder in 68 Year Old Children. Journal of Autism and Developmental Disorders, 46, 3270-3280. https://doi.org/10.1007/s10803-016-2874-6.

Nydén, A., Niklasson, L., Stahlberg, O., Anckarsater, H., Wentz, E., Rastam, M., \& Gillberg, C. (2010). Adults with autism spectrum disorders and ADHD neuropsychological aspects. Research in Developmental Disabilities, 31, 1659-1668. https://doi.org/10.1016/j.ridd.2010.04.010

Ozonoff, S., Cook, I., Coon, H., Dawson, G., Joseph, R.M., Klin, ..., Wrathall, D. (2004). Performance on Cambridge Neuropsychological Test Automated Battery subtests sensitive to frontal lobe function in people with autistic disorder: evidence from the Collaborative Programs of Excellence in Autism network. Journal of Autism and Developmental Disorders, 34, 139-150.

Pitzianti, M., D’Agati, E., Pontis, M., Baratta, A., Casarelli, L., Spiridigliozzi, S., ... \& Pasini, A. (2016). Comorbidity of ADHD and high-functioning autism: A pilot study on the utility of the overflow movements measure. Journal of Psychiatric Practice, 22, 22-30. https://doi.org/10.1097/PRA.0000000000000120.

Polanczyk, G., de Lima, M. S., Horta, B. L., Biederman, J., \& Rohde, L. A. (2007). The worldwide prevalence of ADHD: a systematic review and metaregression analysis. American Journal of Psychiatry, 164, $942-948$.

Rommelse, N. N. J., Geurts, H. M., Franke, B., Buitelaar, J. K., \& Hartman, C. A. (2011). A review on cognitive and brain endophenotypes that may be common in autism spectrum disorder and attention-deficit/hyperactivity disorder and facilitate the search for pleiotropic genes. Neuroscience and Biobehavioral Reviews, 35, 1363-1396. https://doi.org/10.1016/j.neubiorev.2011.02.015

Rommelse, N., Buitelaar, J. K., \& Hartman, C. A. (2017). Structural brain imaging correlates of ASD and ADHD across the lifespan: a hypothesis-generating review on developmental ASD-ADHD subtypes. Journal of Neural Transmission, 124, 259-271. https://doi.org/10.1007/s00702-016-1651-1

Rubia, K., Alegria, A., \& Brinson, H. (2014). Imaging the ADHD brain: disorder- specificity, medication effects and clinical translation. Expert Review of Neurotherapeutics, 14, 519-538. https://doi.org/10.1586/14737175.2014.907526

Simonoff, E., Pickles, A., Charman, T., Chandler, S., Loucas, T., \& Baird, G. (2008). Psychiatric disorders in children with autism spectrum disorders: Prevalence, comorbidity, and associated factors in a population-derived sample. Journal of the American Academy of Child \& Adolescent Psychiatry, 47, 921-929. https://doi.org/10.1097/CHI.0b013e318179964f

Sinzig, J., Bruning, N., Morsch, D., \& Lehmkuhl, G. (2008a). Attention profiles in autistic children with and without comorbid hyperactivity and attention problems. Acta Neuropsychiatrica, 20, $207-215$. https://doi.org/10.1111/j.1601-5215.2008.00292.x

Sinzig, J., Morsch, D., Bruning, N., Schmidt, M. H., \& Lehmkuhl, G. (2008b). Inhibition, flexibility, working memory and planning in autism spectrum disorders with and without comorbid ADHD-symptoms. Child and Adolescent Psychiatry and Mental Health, 2, 4. https://doi.org/10.1186/1753-2000-2-4. 
Stevens, T., Peng, L., \& Barnard-Brak, L. (2016). The comorbidity of ADHD in children diagnosed with autism spectrum disorder. Research in Autism Spectrum Disorders, 31, 11-18. https://doi.org/10.1016/j.rasd.2016.07.003

Stichter, J. P., Herzog, M. J., Owens, S. A., \& Malugen, E. (2016). Manualization, feasibility, and effectiveness of the school-based Social Competence Intervention for Adolescents (SCIA). Psychology in the Schools, 53, 583-600. https://doi.org/10.1002/pits.21928

Takeuchi, A., Ogino, T., Hanafusa, K., Morooka, T., Oka, M., Yorifuji, T., \& Ohtsuka, Y. (2013). Inhibitory function and working memory in attention deficit/hyperactivity disorder and pervasive developmental disorders: does a continuous cognitive gradient explain ADHD and PDD traits?. Acta Medica Okayama, 67, 293-303.

Toplak, M. E., West, R. F., \& Stanovich, K. E. (2013). Practitioner Review: Do performance-based measures and ratings of executive function assess the same construct?. Journal of Child Psychology and Psychiatry, 54, 131-143. https://doi.org/10.1111/jcpp.12001

Tye, C., Asherson, P., Ashwood, K. L., Azadi, B., Bolton, P., \& McLoughlin, G. (2014). Attention and inhibition in children with ASD, ADHD and co-morbid ASD+ ADHD: an event-related potential study. Psychological Medicine, 44, 1101-1116. https://doi.org/10.1017/S0033291713001049

Unterrainer, J. M., Rauh, R., Rahm, B., Hardt, J., Kaller, C. P., Klein, C., ... \& Biscaldi, M. (2016). Development of Planning in Children with High-Functioning Autism Spectrum Disorders and/or Attention Deficit/Hyperactivity Disorder. Autism Research, 9, 739-751. https://doi.org/10.1002/aur.1574

Van der Meer, J. M., Oerlemans, A. M., van Steijn, D. J., Lappenschaar, M. G., de Sonneville, L. M., Buitelaar, J. K., \& Rommelse, N. N. (2012). Are autism spectrum disorder and attention-deficit/hyperactivity disorder different manifestations of one overarching disorder? Cognitive and symptom evidence from a clinical and population-based sample. Journal of the American Academy of Child \& Adolescent Psychiatry, 51, 1160-1172. https://doi.org/10.1016/j.jaac.2012.08.024

Weckstein, S. M., Weckstein, E. J., Parker, C. D., \& Westerman, M. W. (2017). A Retrospective Chart Analysis with Follow-Up of Cogmed Working Memory Training in Children and Adolescents with Autism Spectrum Disorder. Medical Science Monitor Basic Research, 23, 336. https//doi. org/10.12659/MSMBR.904930

Willcutt, E. G., Doyle, A. E., Nigg, J. T., Faraone, S.V., \& Pennington, B. F. (2005). Validity of the executive function theory of attention-deficit/hyperactivity disorder: a meta-analytic review. Biological Psychiatry, 57, 1336-1346. https://doi.org/10.1016/j.biopsych.2005.02.006

Yerys, B. E., Wallace, G. L., Sokoloff, J. L., Shook, D. A., James, J. D., \& Kenworthy, L. (2009). Attention deficit/hyperactivity disorder symptoms moderate cognition and behavior in children with autism spectrum disorders. Autism Research, 2, 322-333. https://doi.org/10.1002/aur.103

\section{Copyrights}

Copyright for this article is retained by the author(s), with first publication rights granted to the journal.

This is an open-access article distributed under the terms and conditions of the Creative Commons Attribution license (http://creativecommons.org/licenses/by/4.0/). 